\title{
Amphiphilic Block Copolymers Bearing Hydrophobic $\gamma$-Tocopherol Groups with Labile Acetal Bond
}

\author{
Shotaro Yukioka ${ }^{1}$, Takuya Kitadume ${ }^{2}$, Suchismita Chatterjee ${ }^{3}$, Gan Ning ${ }^{2}$, Tooru Ooya $^{2} \mathbb{D}$ and

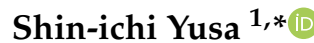 \\ 1 Graduate School of Engineering, University of Hyogo, 2167 Shosha, Himeji, Hyogo 671-2280, Japan; \\ shotaro0326shotaro@gmail.com \\ 2 Graduate School of Engineering, Kobe University, 1-1 Rokkoudai, Nada, Kobe, Hyogo 657-8501, Japan; \\ kitadume@gmail.com (T.K.); Ning@gmail.com (G.N.); ooya@tiger.kobe-u.ac.jp (T.O.) \\ 3 Institute of Material Structure Science, High Energy Accelerator Research Organization, 1-1 Oho, \\ Tsukuba 305-0801, Japan; suchichatterjee@gmail.com \\ * Correspondence: yusa@eng.u-hyogo.ac.jp
}

Received: 2 November 2019; Accepted: 19 December 2019; Published: 25 December 2019

\begin{abstract}
High concentrations of $\gamma$-tocopherol ( $\gamma \mathrm{TCP})$ tend to show antioxidant, anti-inflammatory, and anticancer effects. In this study, we prepared polymer micelles under acidic conditions with a controlled release of $\gamma \mathrm{TCP}$ due to the decomposition of pendant acetal bonds. First, a precursor diblock copolymer composed of poly(ethylene glycol) (PEG) and acrylic acid (AA) was prepared. This was followed by the synthesis of an amphiphilic diblock copolymer ( PEG $_{54}-\mathrm{P}(\mathrm{AA} / \mathrm{VE} 6 / \gamma \mathrm{TCP} 29)_{140}$ ), incorporated into hydrophobic $\gamma \mathrm{TCP}$ pendant groups attached to the main chain through an acetal bond. The prepared $\mathrm{PEG}_{54}-\mathrm{P}(\mathrm{AA} / \mathrm{VE} 6 / \gamma \mathrm{TCP} 29)_{140}$ was further dispersed in water to form polymer micelles composed of hydrophobic cores that were generated from a hydrophobic block containing $\gamma \mathrm{TCPs}$ and hydrophilic shells on the surface. Under acidic conditions, $\gamma \mathrm{TCP}$ was then released from the core of the polymer micelles due to the decomposition of the pendant acetal bonds. In addition, polymer micelles swelled under acidic conditions due to hydration of the core.
\end{abstract}

Keywords: $\gamma$-tocopherol; acetal bond; amphiphilic diblock copolymer; polymer micelles

\section{Introduction}

Amphiphilic diblock copolymers in water form polymer micelles consisting of a hydrophobic core and hydrophilic shell [1-3]. This serves as an effective route to encapsulate hydrophobic anticancer drugs into the core, thereby improving the solubility of the reagents while limiting side effects [4]. As such, the passive targeting of drug-loaded polymer micelles of 10-100 $\mathrm{nm}$ average size can enhance the permeability and retention (EPR) effect $[5,6]$. In general, polymer micelles with a size of several hundred nanometers are unable to penetrate normal vascular walls, while polymer micelles around tumor tissue can penetrate through defected vascular walls (enhanced permeability). This is due to incomplete neovascularization around the tumor and gaps that form between vascular endothelial cells. In addition, polymer micelles cannot be completely removed from the lymphatic tissue around the tumor due to the immaturity of the lymphatic tissue. Therefore, the leaked polymer micelles from tissue vesicular walls tend to accumulate around tumor tissue (enhanced retention). Such a property generated by the accumulation of polymer micelles around tumor tissue is the EPR effect [7]. However, in the passive targeting mechanism, the amount of drugs for delivery to the affected area is low, making the evaluation of the side effects of anticancer drugs non-negligible [8,9].

Recently, cancer-cell apoptosis has been reported using food-derived natural products $[10,11]$. $\gamma$-tocopherol $(\gamma \mathrm{TCP})$ is a type of vitamin E, contained in vegetable oils such as canola, soybean, 
and corn oils. This substance possesses antioxidative and anti-inflammatory effects, and demonstrates the potential to improve cardiovascular disease and prostate cancer [12,13]. According to the literature, an increase in $\gamma \mathrm{TCP}$ concentrations in plasma may decrease the risk of prostate cancer [14]. However, it is well established that the accumulation of excess amounts of vitamin $\mathrm{E}$ in the body by a normal diet is impossible due to the low absorption rate of vitamin $\mathrm{E}$ that is in the range of $21 \%-29 \%$ [15]. Nevertheless, by local administration of more highly concentrated vitamin E, cancer-cell apoptosis can be induced without the use of anticancer drugs.

According to previous studies, the $\mathrm{pH}$ of cancer and healthy cells was determined as 5 and 7.4, respectively [16]. Acetal bonds under acidic conditions can also be readily cleaved into suitably functional moieties [17]. pH-responsive nanoparticles containing acetal linkage within the chemical structure for the controlled release of drugs under acidic conditions have been developed in the last two decades [18-21]. Simo et al. [22] reported that acetal linkage-containing hydrophilic $\mathrm{N}$-(2-(tetrahydoro-2H-pyna-2-yl)oxy)ethyl acrylamide (HEAmTHP) was polymerized via reversible addition-fragmentation chain transfer (RAFT) radical polymerization using a hydrophobic poly(2-hydroxyethyl acrylate) (PHEA) macro-chain transfer agent (CTA) to prepare an amphiphilic diblock copolymer (PHEA-PHEAmTHP). In a subsequent study [23], the encapsulation of a hydrophobic antibiotic substance in the hydrophobic domain of formed PHEA-PHEAmTHP micelles in water was performed. Another study by Gold et al. investigated the effects of attached Amphotericin B to the the cell membrane of micro-organisms, which showed antibiotic property by breaking membrane structures [24]. Under acidic conditions, Amphotericin B was released from the polymer-micelle duet that cleaved the acetal linkages. Feng et al. [25] prepared hyperbranched polyesters (S-hbPE) containing multiple acetal linkages via condensation of 2,2'-(propane-2,2-diylbis(oxy)) diethanol, phosphoryl chloride, and poly(ethylene glycol) monomethyl ether (m-PEG $45-\mathrm{OH})$. Chlorin e6 a photosensitizer for photodynamic therapy (PDT) was encapsulated into S-hbPE to prepare nanoparticles. Chlorin e6 was then released under acidic conditions around tumor tissue attributed to the decomposition of the acetal linkages. As expected, the release of chlorin e6 under acidic conditions around tumor tissue showed the high efficiency of PDT with reduced side effects. Thus, nanocarriers containing acid labile acetal linkages for delivery systems via endosome/lysosome possess advantages such as solubilization of hydrophobic guest molecules, and controlled release in the acidic conditions around tumor tissue.

In this study, we first prepared a precursor diblock copolymer (PEG $54-\mathrm{PAA}_{140}$ ) composed of biocompatible poly(ethylene glycol) (PEG) and poly(acrylic acid) (PAA) blocks. This was followed by the preparation of a diblock copolymer $\left(\mathrm{PEG}_{54}-\mathrm{P}(\mathrm{AA} / \mathrm{VE} 35)_{140}\right)$ via incorporation of vinyl ether (VE) groups to the pendant carboxylic acid groups of the PAA block through esterification. Finally, a diblock copolymer (PEG $\left.54-\mathrm{P}(\mathrm{AA} / \mathrm{VE} 6 / \gamma \mathrm{TCP} 29)_{140}\right)$ was prepared via introduction of hydrophobic $\gamma$ TCP groups onto the pendant VE groups by acetal linkage (Figure 1). The plane and subscript numbers express the content (mol\%) and degree of polymerization (DP), respectively. In addition, aqueous solutions of $\mathrm{PEG}_{54}-\mathrm{P}(\mathrm{AA} / \mathrm{VE} 6 / \gamma \mathrm{TCP} 29)_{140}$ were formulated to produce polymer micelles via hydrophobic interactions of pendant $\gamma \mathrm{TCP}$ (Figure 2). Under acidic conditions, partial release of $\gamma \mathrm{TCP}$ occurred due to the decomposition of the pendant acetal linkages. This was also attributed to the slight swelling of the polymer micelles since hydrophobicity of the micelles decreased with the release of hydrophobic $\gamma$ TCP. This suggests that the release of highly concentrated $\gamma$ TCP by the polymer micelles under acidic conditions may lead to cancer-cell apoptosis without the use of anticancer drugs. 


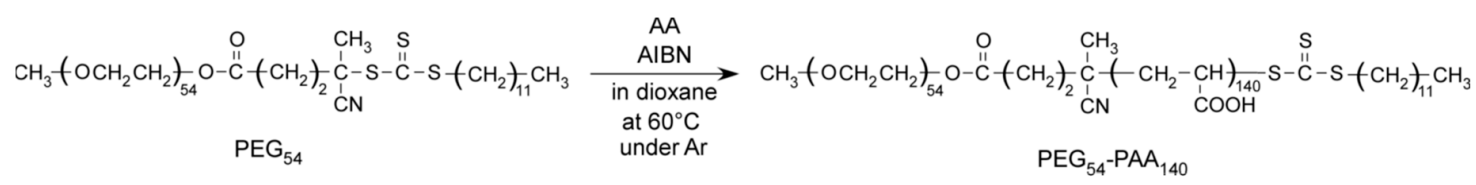
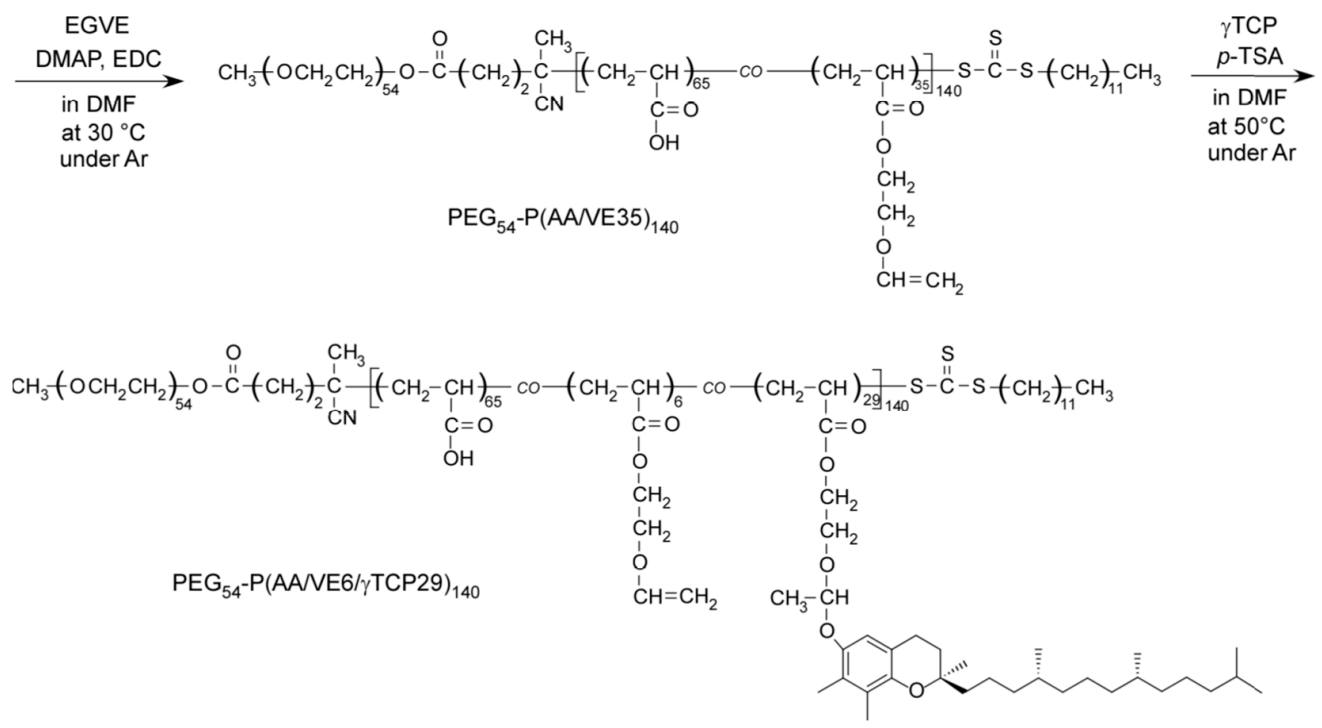

Figure 1. Synthesis of $\mathrm{PEG}_{54}-\mathrm{PAA}_{140}, \mathrm{PEG}_{54}-\mathrm{P}(\mathrm{AA} / \mathrm{VE} 35)_{140}$, and $\mathrm{PEG}_{54}-\mathrm{P}(\mathrm{AA} / \mathrm{VE6} / \gamma \mathrm{TCP} 29)_{140}$.

(a)
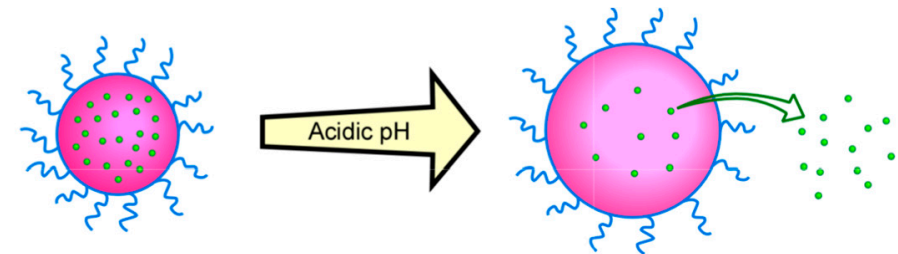

$\gamma$ TCP-containing micelle

$\mathrm{pH}$-triggered acetal hydrolysis and release of $\gamma \mathrm{TCP}$

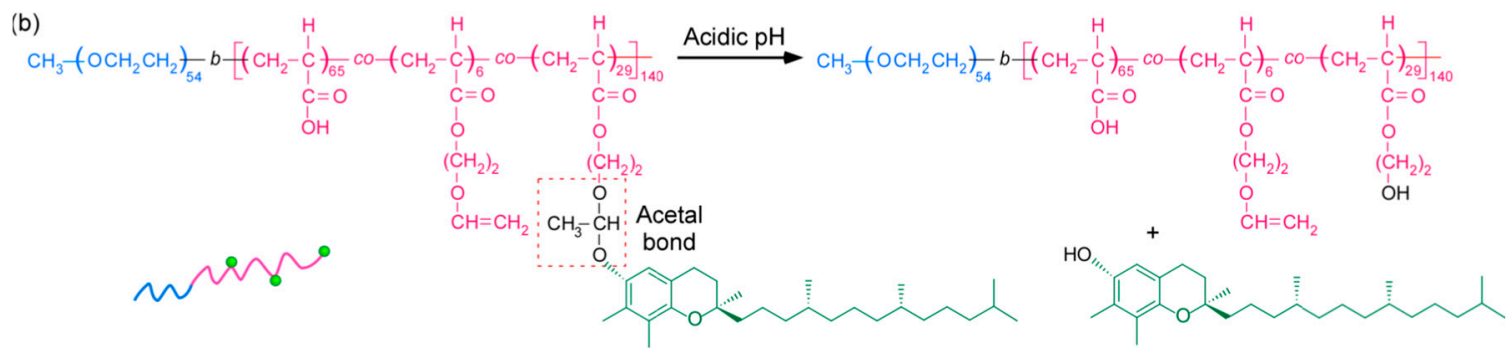

Figure 2. (a) Micelle formation and release of $\gamma \mathrm{TCP}$ in acidic aqueous solution; (b) chemical structure of $\mathrm{PEG}_{54}-\mathrm{P}(\mathrm{AA} / \mathrm{VE} 6 / \gamma \mathrm{TCP} 29)_{140}$.

\section{Materials and Methods}

\subsection{Materials}

Poly(ethylene glycol) methylether (4-cyano-4-pentanoate dodecyltrithiocarbonate) (PEG ${ }_{54}$, $\left.M_{\mathrm{n}}=2.40 \times 10^{3} \mathrm{~g} / \mathrm{mol}\right)$ and $\gamma$-tocopherol $(\gamma \mathrm{TCP}, 96 \%)$ were purchased from Sigma Aldrich (St. Louis, MO, USA); 1-ethyl-3-(3-dimethylaminopropyl)carbodiimide hydrochloride (EDC, 98\%) and $\mathrm{N}, \mathrm{N}$-dimethyl-4-aminopyridine (DMAP, 99\%) were procured from Fujifilm Wako Pure Chemicals (Osaka, Japan). Ethylene glycol mono-vinyl ether (EGVE, 98\%) and $p$-toluenesulfonic acid ( $p$-TSA, 98\%) were supplied by Tokyo Chemical Industry (Tokyo, Japan). All reagents above were used as received without further purification. We used 2,2'-azobisisobutyronitrile (AIBN, 98\%) from Sigma Aldrich (St. Louis, MO, USA) after recrystallization using methanol. Acrylic acid (AA, 98\%), 1,4-dioxane 
(99\%), and N,N-dimethylformamide (DMF, 99\%) from Fujifilm Wako Pure Chemicals (Osaka, Japan) were used after vacuum distillation. Water was purified with an ion-exchange column system. Other reagents were used as received.

\section{2. $P E G_{54}-P A A_{140}$ Synthesis}

PEG $_{54}(2.00 \mathrm{~g}, 0.833 \mathrm{mmol}), \mathrm{AA}(9.00 \mathrm{~g}, 124 \mathrm{mmol})$, and AIBN (30.5 mg, $\left.0.186 \mathrm{mmol}\right)$ were dissolved in 1, 4-dioxane (50 mL). The solution was deoxygenated by purging argon gas for $30 \mathrm{~min}$. Polymerization was carried out at $60{ }^{\circ} \mathrm{C}$ for $16 \mathrm{~h}$. The conversion of AA estimated from ${ }^{1} \mathrm{H}$ NMR was $98.2 \%$. The polymerization mixture was dialyzed against pure water for 2 days. The polymer $\left(\mathrm{PEG}_{54}-\mathrm{PAA}_{140}\right)$ was recovered by a freeze-drying method $(8.70 \mathrm{~g}, 79.1 \%)$. DP for PAA block and number-average molecular weight $\left(M_{n}\right)$ for $\mathrm{PEG}_{54}-\mathrm{PAA}_{140}$ were estimated using ${ }^{1} \mathrm{H}$ NMR as 140 and $1.26 \times 10^{4} \mathrm{~g} / \mathrm{mol}$, respectively. While, $M_{\mathrm{n}}$ and molecular-weight distribution $\left(M_{\mathrm{w}} / M_{\mathrm{n}}\right)$ were calculated as $1.25 \times 10^{4} \mathrm{~g} / \mathrm{mol}$ and 1.36 , respectively, using gel-permeation chromatography (GPC).

\subsection{Synthesis of $P E G_{54}-P(A A / V E 35)_{140}$}

We have used the conventional esterification method using EDC [26]. PEG $54-\mathrm{PAA}_{140}$ (134 mg, $1.50 \mathrm{mmol}$ of COOH unit), DMAP ( $91.8 \mathrm{mg}, 0.751 \mathrm{mmol})$, and EDC ( $860 \mathrm{mg}, 4.49 \mathrm{mmol})$ were dissolved in DMF $(20 \mathrm{~mL})$. The solution was stirred at $30^{\circ} \mathrm{C}$ for $10 \mathrm{~h}$ under an argon atmosphere, and then EGVE $(0.667 \mathrm{~mL}, 7.55 \mathrm{mmol})$ was added to the solution. The solution was stirred at $30^{\circ} \mathrm{C}$ for $24 \mathrm{~h}$. Once the reaction was complete, the solution was dialyzed against pure water for three days. The prepared polymer $\left(\mathrm{PEG}_{54} \mathrm{P}(\mathrm{AA} / \mathrm{VE} 35)_{140}\right)$ was recovered by a freeze-drying method $(0.15 \mathrm{~g}, 56.6 \%)$. The $M_{\mathrm{n}}$ of $\mathrm{PEG}_{54} \mathrm{P}(\mathrm{AA} / \mathrm{VE} 35)_{140}$ estimated from ${ }^{1} \mathrm{H}$ NMR was determined as $1.67 \times 10^{4} \mathrm{~g} / \mathrm{mol} . M_{\mathrm{n}}$ and $M_{\mathrm{w}} / M_{\mathrm{n}}$ estimated using GPC were determined as $7.02 \times 10^{3} \mathrm{~g} / \mathrm{mol}$ and 1.38 , respectively. The exchange ratio from the pendant carboxylic acid in the PAA block to the VE group was $35.0 \%$ estimated from ${ }^{1} \mathrm{H}$ NMR.

\section{4. $P E G_{54}-P(A A / V E 6 / \gamma T C P 29)_{140}$ Synthesis}

Conjugation of $\gamma \mathrm{TCP}$ onto $\mathrm{PEG}_{54}-\mathrm{P}(\mathrm{AA} / \mathrm{VE} 35)_{140}$ via an acid-labile acetal bond was prepared according to a previously reported method [17]. PEG $_{54}-\mathrm{P}(\mathrm{AA} / \mathrm{VE} 35)_{140}(62.5 \mathrm{mg}, 180 \mu \mathrm{mol}$ of VE unit), $\gamma$ TCP $(25.0 \mathrm{mg}, 60.0 \mu \mathrm{mol})$, and $p$-TSA $(0.56 \mathrm{mg}, 2.94 \mu \mathrm{mol})$ were dissolved in DMF $(10 \mathrm{~mL})$. Molecular sieves $4 \mathrm{~A}(1.00 \mathrm{~g})$ was added to the solution. The reaction was carried out at $50{ }^{\circ} \mathrm{C}$ for 4 days under an argon atmosphere. Molecular sieves were removed by filtration, and the solution was dialyzed against pure water for 2 days. The polymer ( $\left.\mathrm{PEG}_{54} \mathrm{P}(\mathrm{AA} / \mathrm{VE} 6 / \gamma \mathrm{TCP} 29)_{140}\right)$ was recovered by a freeze-drying method $(80.9 \mathrm{mg}, 92.5 \%) . \quad M_{\mathrm{n}}$ for $\mathrm{PEG}_{54} \mathrm{P}(\mathrm{AA} / \mathrm{VE} 6 / \gamma \mathrm{TCP} 29)_{140}$ using ${ }^{1} \mathrm{H}$ NMR was estimated as $1.96 \times 10^{4} \mathrm{~g} / \mathrm{mol} . M_{\mathrm{n}}$ and $M_{\mathrm{W}} / M_{\mathrm{n}}$ estimated using GPC were determined as $1.02 \times 10^{4} \mathrm{~g} / \mathrm{mol}$ and 1.47 , respectively. The exchange ratio from the VE to $\gamma \mathrm{TCP}$ was calculated as $82.9 \%$ from ${ }^{1} \mathrm{H}$ NMR.

\subsection{Measurements}

${ }^{1} \mathrm{H}$ NMR spectra were measured with a Bruker DRX-500 (Billerica, AM, USA) at room temperature. The block copolymer sample solutions for the ${ }^{1} \mathrm{H}$ NMR measurements were prepared in dimethylsulfoxide- $d_{6}$ (DMSO- $d_{6}$ ). GPC measurements were performed using Shodex (Tokyo, Japan) Asahipak GF-1G guard column and GF-7M HQ column at $40{ }^{\circ} \mathrm{C}$ with a refractive index detector and yielded a phosphate buffer solution (PBS) of $\mathrm{pH} 9$ containing $10 \% v / v$ of acetonitrile at $0.6 \mathrm{~mL} / \mathrm{min}$ in the developing solvent. Determination of $M_{\mathrm{n}}$ and $M_{\mathrm{w}} / M_{\mathrm{n}}$ according to GPC were calibrated using standard sodium poly(styrene sulfonate)s. Hydrodynamic radius $\left(R_{\mathrm{h}}\right)$ and scattered light intensity (LSI) were estimated using a Malvern (Malvern, UK) Zetasizer Nano ZS-ZEN3600 equipped with a He-Ne laser source $(4 \mathrm{~mW}$ at $632.8 \mathrm{~nm})$ at $25^{\circ} \mathrm{C}$. The sample solutions for light-scattering measurements were filtered through a filter with pore-size diameter of $0.8 \mu \mathrm{m}$. Static light scattering (SLS) measurements were carried out with Otsuka Electronics (Osaka, Japan) DLS 7000 at $25^{\circ} \mathrm{C}$. The He-Ne laser $(10 \mathrm{~mW}$ at $632.8 \mathrm{~nm}$ ) was used as a light source. Weight average molecular weight $\left(M_{\mathrm{W}}\right)$ and radius of gyration $\left(R_{\mathrm{g}}\right)$ were calculated from a Debye plot at 1 polymer concentration. The Rayleigh ratio of toluene was 
used in instrument calibration. Refractive index increment against the polymer concentration $\left(\mathrm{d} n / \mathrm{d} C_{\mathrm{p}}\right)$ at $633 \mathrm{~nm}$ was determined using Otsuka Electronics DRM-3000 differential refraction meter at $25^{\circ} \mathrm{C}$. TEM observations were performed with a JEOL (Tokyo, Japan) JEM-2100 at an accelerating voltage of $160 \mathrm{kV}$. Prior to TEM analysis, the sample was prepared by placing 1 drop of the aqueous solution on a copper grid coated with Formvar. Excess water was blotted using filter paper. Samples were stained by sodium phosphotungstate and dried under vacuum for a period of 1 day.

\section{Results and Discussion}

\section{1. $P E G_{54}-P(A A / V E 6 / \gamma T C P 29)_{140}$ Preparation}

The conversion of AA by RAFT polymerization using PEG $_{54}$ macro-CTA was determined as $98.2 \%$ estimated from the decrease of ${ }^{1} \mathrm{H}$ NMR integral area intensity ratio of the vinyl group in AA after polymerization. The DP of the PAA block was calculated to be 140 from the area integral intensity ratio of peaks attributed to ethylene oxide protons in $\mathrm{PEG}_{54}$ at $3.7 \mathrm{ppm}$ and the main chain protons in PAA at $2.3 \mathrm{ppm}$ (Figure 3a). The introduction of the pendant vinyl groups in $\mathrm{PEG}_{54}-\mathrm{P}(\mathrm{AA} / \mathrm{VE} 35)_{140}$ were confirmed by the observed ${ }^{1} \mathrm{H}$ NMR signal at $6.5 \mathrm{ppm}$ attributed to VE (Figure $3 \mathrm{~b}$ ). The reaction rate from the pendant carboxylic acid to the vinyl groups, calculated as $34.8 \%$, was estimated from the integral intensity ratios of the attributed peaks to the main chain protons of $\mathrm{PAA}_{140}$ at $2.3 \mathrm{ppm}$ and the vinyl protons in EGVE at $6.5 \mathrm{ppm}$. This result indicated that about 49 pendant vinyl groups were introduced into one polymer chain of $\mathrm{PEG}_{54}-\mathrm{P}(\mathrm{AA} / \mathrm{VE} 35)_{140}$. The protons attributed to the terminal methyl at $0.8 \mathrm{ppm}$, benzyl at $2.0 \mathrm{ppm}$, and phenyl protons at $6.3 \mathrm{ppm}$ in the pendant $\gamma \mathrm{TCP}$ could be observed from a PEG $54-\mathrm{P}(\mathrm{AA} / \mathrm{VE} 6 / \gamma \mathrm{TCP} 29)_{140}{ }^{1} \mathrm{H}$ NMR spectrum (Figure 3c). The introduction rate of $\gamma \mathrm{TCP}$ in $\mathrm{PEG}_{54}-\mathrm{P}(\mathrm{AA} / \mathrm{VE} 6 / \gamma \mathrm{TCP} 29)_{140}$ was calculated as $83.3 \%$ estimated from the integral intensity ratio of the unreacted pendant vinyl protons in $\mathrm{PEG}_{54}-\mathrm{P}(\mathrm{AA} / \mathrm{VE} 35)_{140}$ at $6.5 \mathrm{ppm}$ and phenyl protons in $\gamma \mathrm{TCP}$ at $6.3 \mathrm{ppm}$ [27]. This result indicated that about 41 pendant $\gamma \mathrm{TCPs}$ were introduced into a single polymer chain of $\mathrm{PEG}_{54} \mathrm{P}(\mathrm{AA} / \mathrm{VE} 6 / \gamma \mathrm{TCP} 29)_{140}$. The theoretical $M_{\mathrm{n}}$ of each polymer was calculated using the following equation:

$$
M_{\mathrm{n}}(\text { theo })=\frac{[\mathrm{M}]_{0}}{[\mathrm{CTA}]_{0}} \times \frac{p}{100} \times M_{\mathrm{m}}+M_{\mathrm{CTA}}
$$

where $[\mathrm{M}]_{0}$ and $[\mathrm{CTA}]_{0}$ are the initial molar concentrations of monomer and CTA, respectively, $p$ is the conversion of the monomer, and $M_{\mathrm{m}}$ and $M_{\mathrm{CTA}}$ are the molecular weights of the monomer and CTA, respectively.

The GPC-determined $M_{\mathrm{n}}$ values of $\mathrm{PEG}_{54}-\mathrm{PAA}_{140}, \mathrm{PEG}_{54}-\mathrm{P}(\mathrm{AA} / \mathrm{VE} 35)_{140}$, and $\mathrm{PEG}_{54}-\mathrm{P}(\mathrm{AA} /$ VE6/ $\gamma$ TCP29) $)_{140}$ were $1.25 \times 10^{4}, 7.02 \times 10^{3}$, and $1.02 \times 10^{4} \mathrm{~g} / \mathrm{mol}$, respectively (Figure 4). Due to the unexpected interactions between polymers within the GPC column, and the difference between structures of the measured polymer and the standard polymer, accurate molecular weight could not be estimated [28,29]. The $M_{\mathrm{w}} / M_{\mathrm{n}}$ values of $\mathrm{PEG}_{54}-\mathrm{PAA}_{140}, \mathrm{PEG}_{54}-\mathrm{P}(\mathrm{AA} / \mathrm{VE} 35)_{140}$, and $\mathrm{PEG}_{54}-\mathrm{P}(\mathrm{AA} / \mathrm{VE} 6 / \gamma \mathrm{TCP} 29)_{140}$ were relatively narrow, obtained as $1.36,1.38$, and 1.47 , respectively. Table 1 summarizes the molecular weight and $M_{\mathrm{W}} / M_{\mathrm{n}}$ of each polymer. 


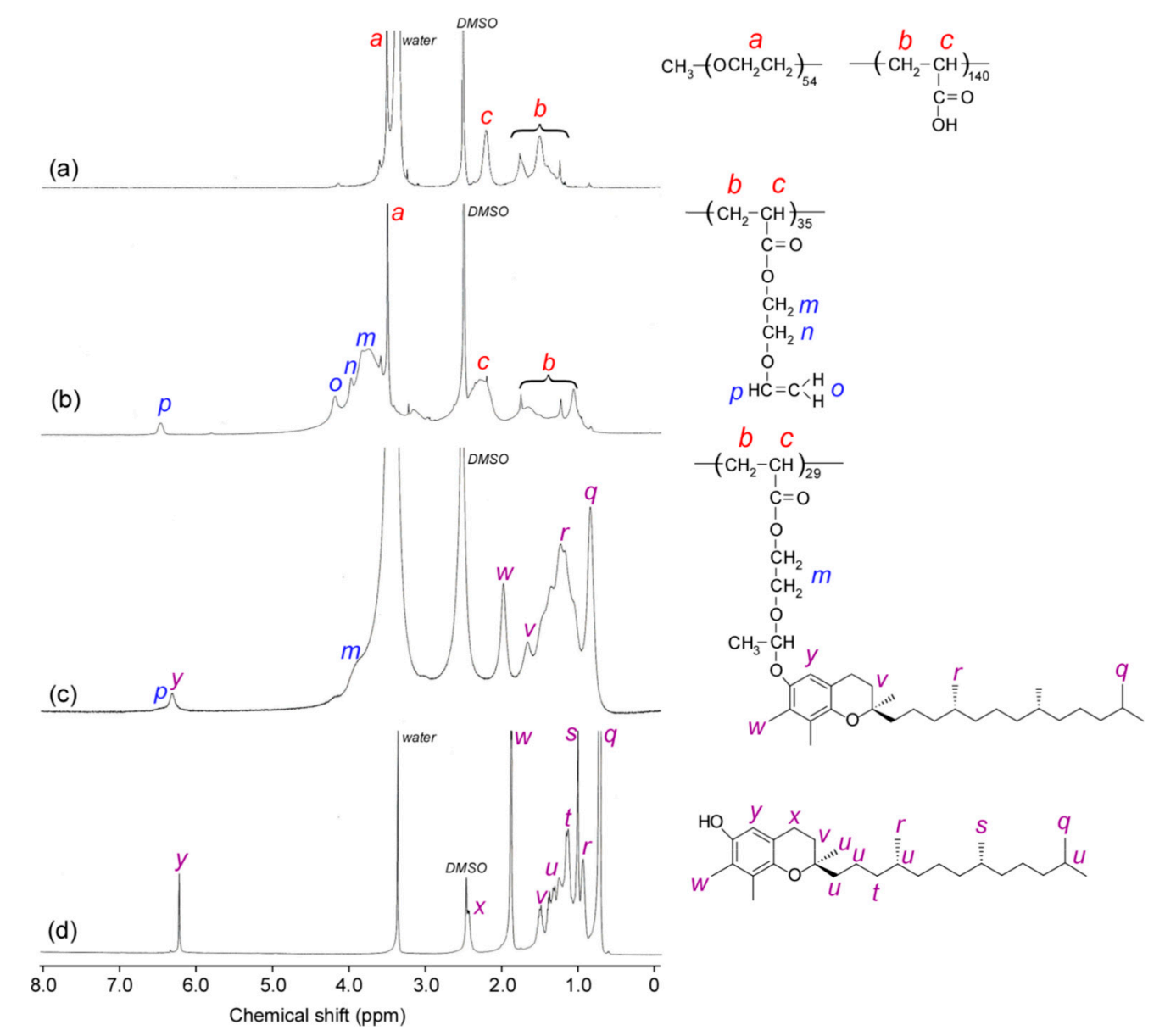

Figure 3. ${ }^{1} \mathrm{H}$ NMR spectra of (a) $\mathrm{PEG}_{54}-\mathrm{PAA}_{140}$, (b) $\mathrm{PEG}_{54}-\mathrm{P}(\mathrm{AA} / \mathrm{VE} 35)_{140}$, (c) $\mathrm{PEG}_{54}-\mathrm{P}(\mathrm{AA} / \mathrm{VE6} /$ $\gamma \mathrm{TCP} 29)_{140}$, and (d) $\gamma \mathrm{TCP}$ in DMSO- $d_{6}$.

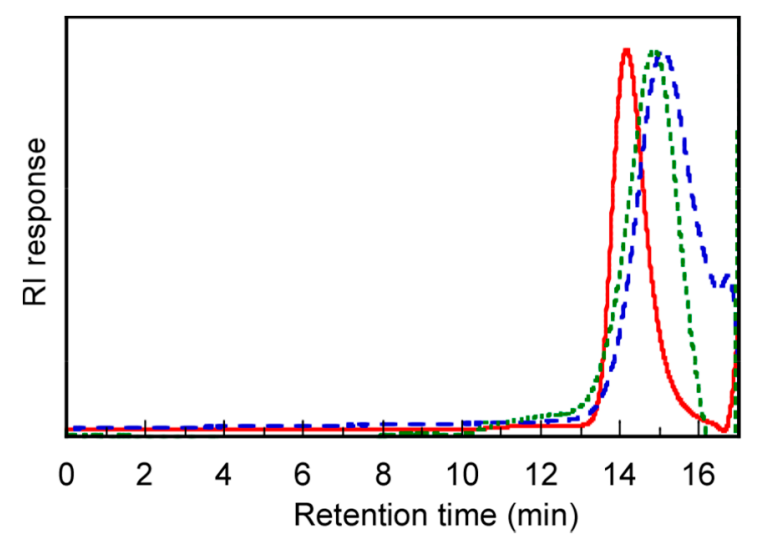

Figure 4. Gel-permeation chromatography (GPC) elution curves of $\mathrm{PEG}_{54}-\mathrm{PAA}_{140}$ (一), $\mathrm{PEG}_{54}-\mathrm{P}(\mathrm{AA} / \mathrm{VE} 35)_{140}(--)$, and $\mathrm{PEG}_{54}-\mathrm{P}(\mathrm{AA} / \mathrm{VE} 6 / \gamma \mathrm{TCP} 29)_{140}(-)$ at $40{ }^{\circ} \mathrm{C}$ using a phosphate buffer solution (PBS) at $\mathrm{pH} 9$ containing $10 \%$ v/v acetonitrile as the eluent. 
Table 1. Number-average molecular weight $\left(M_{\mathrm{n}}\right)$ and $M_{\mathrm{n}}$ distribution $\left(M_{\mathrm{w}} / M_{\mathrm{n}}\right)$.

\begin{tabular}{|c|c|c|c|c|}
\hline Sample & $\begin{array}{l}\text { heoretical } M_{\mathrm{n}} \times 10^{4} \\
\quad(\mathrm{~g} / \mathrm{mol})\end{array}$ & $\underset{(\mathrm{g} / \mathrm{mol})}{{ }^{1} \mathrm{H} \underset{\mathrm{NMR}}{\mathrm{NM}} M_{\mathrm{n}} \times 10^{4}}$ & $\begin{array}{l}\text { GPC } M_{n} \times 10^{4} \\
(\mathrm{~g} / \mathrm{mol})\end{array}$ & $M_{\mathrm{w}} / M_{\mathrm{n}}$ \\
\hline $\mathrm{PEG}_{54}-\mathrm{PAA}_{140}$ & 1.30 & 1.26 & 1.25 & 1.36 \\
\hline $\mathrm{PEG}_{54}-\mathrm{P}(\mathrm{AA} / \mathrm{VE} 35)_{140}$ & 1.54 & 1.67 & 0.702 & 1.38 \\
\hline $\mathrm{PEG}_{54}-\mathrm{P}(\mathrm{AA} / \mathrm{VE} 6 / \gamma \mathrm{TCP} 29)_{140}$ & 1.83 & 1.96 & 1.02 & 1.47 \\
\hline
\end{tabular}

\section{2. $P E G_{54}-P(A A / V E 6 / \gamma T C P 29)_{140}$ Micelle Formation}

The $R_{\mathrm{h}}$ and LSI of the polymers were measured at $C_{\mathrm{p}}=0.10 \mathrm{~g} / \mathrm{L}$ in a PBS buffer of $\mathrm{pH} 7.4$ at $25{ }^{\circ} \mathrm{C}$ to confirm aggregation-state changes for $\mathrm{PEG}_{54}-\mathrm{PAA}_{140}, \mathrm{PEG}_{54}-\mathrm{P}(\mathrm{AA} / \mathrm{VE} 35)_{140}$, and $\mathrm{PEG}_{54}-\mathrm{P}(\mathrm{AA} / \mathrm{VE} 6 / \gamma \mathrm{TCP} 29)_{140}$ (Figure 5$)$. The $R_{\mathrm{h}}$ values of $\mathrm{PEG}_{54}-\mathrm{PAA}_{140}$ and $\mathrm{PEG}_{54}-\mathrm{P}(\mathrm{AA} / \mathrm{VE} 35)_{140}$ were 4.4 and $5.8 \mathrm{~nm}$, respectively. The LSI values of $\mathrm{PEG}_{54}-\mathrm{PAA}_{140}$ and $\mathrm{PEG}_{54}-\mathrm{P}(\mathrm{AA} / \mathrm{VE} 35)_{140}$ were estimated as 40.4 and $83.0 \mathrm{Kcps}$, respectively. These polymers may dissolve in PBS to form unimers due to their small $R_{\mathrm{h}}$ and LSI values. On the other hand, the $R_{\mathrm{h}}$ and LSI of $\mathrm{PEG}_{54}-\mathrm{P}(\mathrm{AA} / \mathrm{VE} 6 / \gamma \mathrm{TCP} 29)_{140}$ increased to $84.1 \mathrm{~nm}$ and $709 \mathrm{Kcps}$, suggesting the formation of polymer micelles. These polymer micelles were formed due to the hydrophobic interaction between pendant $\gamma \mathrm{TCP}$ groups, which were composed of a hydrophobic $\mathrm{P}(\mathrm{AA} / \mathrm{VE} 6 / \gamma \mathrm{TCP} 29)_{140}$ core and hydrophilic PEG $_{54}$ shells. The end-to-end distance of the $\mathrm{PEG}_{54}-\mathrm{P}(\mathrm{AA} / \mathrm{VE6} / \gamma \mathrm{TCP} 29)_{140}$ polymer chain was estimated as $53.4 \mathrm{~nm}$, assuming that the lengths of the vinyl monomer unit and the PEG chain were 0.25 and $18.4 \mathrm{~nm}$, respectively [30-32]. The $R_{\mathrm{h}}$ value of the polymer micelle was calculated as $84.1 \mathrm{~nm}$, which was larger than the end-to-end distance of PEG ${ }_{54}-\mathrm{P}(\mathrm{AA} / \mathrm{VE} 6 / \gamma \mathrm{TCP} 29)_{140}(=53.4 \mathrm{~nm})$. Therefore, polymers could not form simple spherical core-shell structures. The polymers may form intermicellar aggregates or large compound micelles.

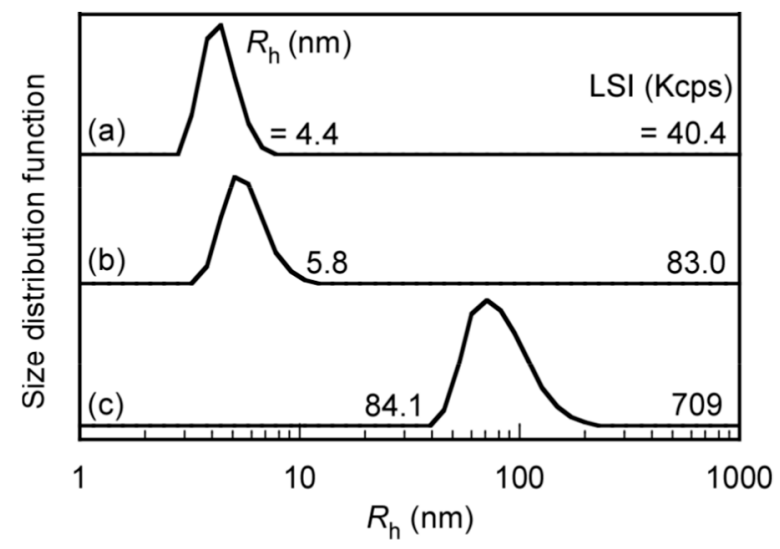

Figure 5. Hydrodynamic-radius $\left(R_{\mathrm{h}}\right)$ distributions for (a) $\mathrm{PEG}_{54}-\mathrm{PAA}_{140}$, (b) $\mathrm{PEG}_{54}-\mathrm{P}(\mathrm{AA} / \mathrm{VE} 35)_{140}$, and (c) $\mathrm{PEG}_{54}-\mathrm{P}(\mathrm{AA} / \mathrm{VE} 6 / \gamma \mathrm{TCP} 29)_{140}$ in PBS at $C_{\mathrm{p}}=0.10 \mathrm{~g} / \mathrm{L}$.

To characterize the polymer micelles formed from PEG $_{54}-\mathrm{P}(\mathrm{AA} / \mathrm{VE} 6 / \gamma \mathrm{TCP} 29)_{140}$ in the PBS buffer, SLS measurements were performed (Figure 6). Using SLS, the apparent $M_{\mathrm{W}}$ and $R_{\mathrm{g}}$ were estimated from the Debye plot (Table 2). The measured $\mathrm{d} n / \mathrm{d} C_{\mathrm{p}}(=1.70 \mathrm{~mL} / \mathrm{g})$ of the polymer micelles were then used to estimate the apparent $M_{\mathrm{W}}$. The aggregation number $\left(N_{\mathrm{agg}}\right)$, which is the number of polymer chains to form one micelle, was estimated using the following equation:

$$
N_{\mathrm{agg}}=\frac{M_{\mathrm{w}}(\mathrm{SLS})}{M_{\mathrm{w}} / M_{\mathrm{n}} \times M_{\mathrm{n}}(\mathrm{NMR})}
$$

$N_{\text {agg }}$ was estimated as 248 using $M_{\mathrm{w}}\left(=7.15 \times 10^{6} \mathrm{~g} / \mathrm{mol}\right), M_{\mathrm{w}} / M_{\mathrm{n}}(=1.47)$, and $M_{\mathrm{n}}(\mathrm{NMR})$ $\left(=1.96 \times 10^{6} \mathrm{~g} / \mathrm{mol}\right)$ determined by SLS. Theoretically, $R_{\mathrm{g}} / R_{\mathrm{h}}$ depends on the shape and polydispersity of the micelles, for instance, hard sphere as 0.775 , monodisperse sphere as 1.0, and rodlike shape as 
more than 2.0 [33-35]. The $R_{\mathrm{g}} / R_{\mathrm{h}}$ of the polymer micelles formed from $\mathrm{PEG}_{54}-\mathrm{P}(\mathrm{AA} / \mathrm{VE} 6 / \gamma \mathrm{TCP} 29)_{140}$ was calculated as 1.32, which is close to 1.0. Therefore, the polymers formed spherical micelles.

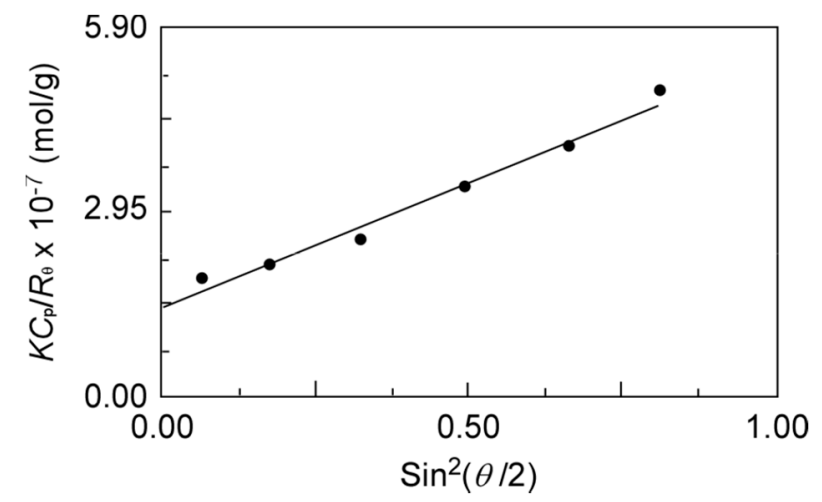

Figure 6. Debye plot for $\mathrm{PEG}_{54}-\mathrm{P}(\mathrm{AA} / \mathrm{VE6} / \gamma \mathrm{TCP} 29)_{140}$ in $\mathrm{PBS}$ at fixed $C_{\mathrm{p}}(=0.10 \mathrm{~g} / \mathrm{L}) . K$, optical constant; $C_{\mathrm{p}}$, polymer concentration; $R_{\theta}$, difference between Rayleigh ratio of solution and solvent; and $\theta$, scattering angle.

Table 2. Dynamic and static light-scattering data of $\mathrm{PEG}_{54}-\mathrm{P}(\mathrm{AA} / \mathrm{VE} 6 / \gamma \mathrm{TCP} 29)_{140}$ in PBS.

\begin{tabular}{ccccccc}
\hline Sample & $\begin{array}{c}\text { SLS } \boldsymbol{M}_{\mathbf{w}} \times \mathbf{1 0}^{\mathbf{6}} \\
(\mathrm{g} / \mathbf{m o l})\end{array}$ & $\boldsymbol{N}_{\mathrm{agg}}$ & $\boldsymbol{R}_{\mathrm{g}}(\mathbf{n m})$ & $\boldsymbol{R}_{\mathrm{h}}(\mathrm{nm})$ & $\boldsymbol{R}_{\mathrm{g}} / \boldsymbol{R}_{\mathrm{h}}$ & $\mathrm{d} n / \mathrm{d} C_{\mathrm{p}}(\mathbf{m L} / \mathbf{g})$ \\
\hline $\mathrm{PEG}_{54}-\mathrm{P}(\mathrm{AA} / \mathrm{VE} 6 / \gamma \mathrm{TCP} 29)_{140}$ & 7.15 & 248 & 111 & 84.1 & 1.32 & 1.70 \\
\hline
\end{tabular}

\subsection{Micelle Decomposition in Acidic Condition}

To evaluate the time dependence on micelle size and density formed from $\mathrm{PEG}_{54}-\mathrm{P}(\mathrm{AA} / \mathrm{VE6} / \gamma \mathrm{TCP} 29)_{140}$ in acetate buffer of $\mathrm{pH} 5.2(0.01 \mathrm{M}), R_{\mathrm{h}}$ and LSI changes were monitored at $25{ }^{\circ} \mathrm{C}$ (Figure 7). At constant particle size, density depended on the LSI. As a reference experiment, the time dependence on $R_{\mathrm{h}}$ and LSI of the polymer micelles in a PBS buffer of pH 7.4 (0.01 M) were also monitored. $R_{\mathrm{h}}$ increased with increasing time at $\mathrm{pH} 5.2$. $R_{\mathrm{h}}$ values just after preparation and after $60 \mathrm{~h}$ at pH 5.2 were determined as 81.0 and $107.0 \mathrm{~nm}$, respectively. LSI values of just after preparation and after $60 \mathrm{~h}$ at pH 5.2 were estimated as 693 and $321 \mathrm{Kcps}$, respectively. The LSI were observed to decrease with increasing time. At pH 5.2, the pendant acetal bonds decomposed to release the hydrophobic $\gamma \mathrm{TCP}$ from the polymer micelles. As a result, hydroxyl groups were generated at the pendant groups. However, not all pendant acetal bonds were decomposed at pH 5.2. However, an increase in $R_{\mathrm{h}}$ and decrease of the LSI was due to decreasing densities observed at $\mathrm{pH}$ 5.2, attributed to the hydration and then swelling of the core of the polymer micelles. Oho et al. [36] reported that $\gamma \mathrm{TCP}$ is relatively stable against acidic conditions. The released $\gamma \mathrm{TCP}$ from the polymer in a buffer at $\mathrm{pH}=5.2$ may not be decomposed.

At $\mathrm{pH}$ 7.4, the $R_{\mathrm{h}}$ values of the micelles just after preparation and after $60 \mathrm{~h}$ were calculated as 81.5 and $83.8 \mathrm{~nm}$, respectively. The LSI of the micelles slightly decreased with increasing time. The values of LSI just after preparation and after $60 \mathrm{~h}$ were obtained as 695 and $492 \mathrm{Kcps}$. These observations suggest that the pendant acetal groups slightly decomposed at $\mathrm{pH}$ 7.4. Compared to the time dependence of $R_{\mathrm{h}}$ and LSI at pH 5.2 and 7.4, $\gamma \mathrm{TCP}$ was effectively released due to the decomposition of the pendant acetal bonds.

The micelles of $\mathrm{PEG}_{54}-\mathrm{P}(\mathrm{AA} / \mathrm{VE} 6 / \gamma \mathrm{TCP} 29)_{140}$ in $\mathrm{PBS}$ of $\mathrm{pH} 7.4$ were observed with Transmission electron microscopy (TEM, Figure S1). The radius $\left(R_{\text {TEM }}\right)$ estimated from the TEM image was $72.1 \pm 12 \mathrm{~nm}$. $R_{\text {TEM }}$ was calculated from a randomly selected 50 particles $(N=50) . R_{\text {TEM }}$ was smaller than the $R_{\mathrm{h}}$ values determined by light-scattering measurements because the aggregates shrank during the drying process in preparation for TEM measurements. The micelles of PEG54-P(AA/VE6/ $\gamma$ TCP29)140 in the acetate buffer of $\mathrm{pH} 5.2$ just after preparation and after $60 \mathrm{~h}$ were observed using TEM to confirm 
the shape changes of the micelles (Figure 8 and Figure S1). Both samples were close to spherical shapes. The $R_{\text {TEM }}$ values for just after preparation and after $60 \mathrm{~h}$ were estimated as $77.9 \pm 18$ and $113 \pm 32 \mathrm{~nm}$, respectively. This result suggests that the swollen micelles were due to increasing core hydrophilicity at $\mathrm{pH} 5.2$ after $60 \mathrm{~h}$. The particle-size range of the polymer aggregates after $60 \mathrm{~h}$ was larger than that just after preparation. This observation suggests that decomposition of the pendant acetal linkage was not uniform.
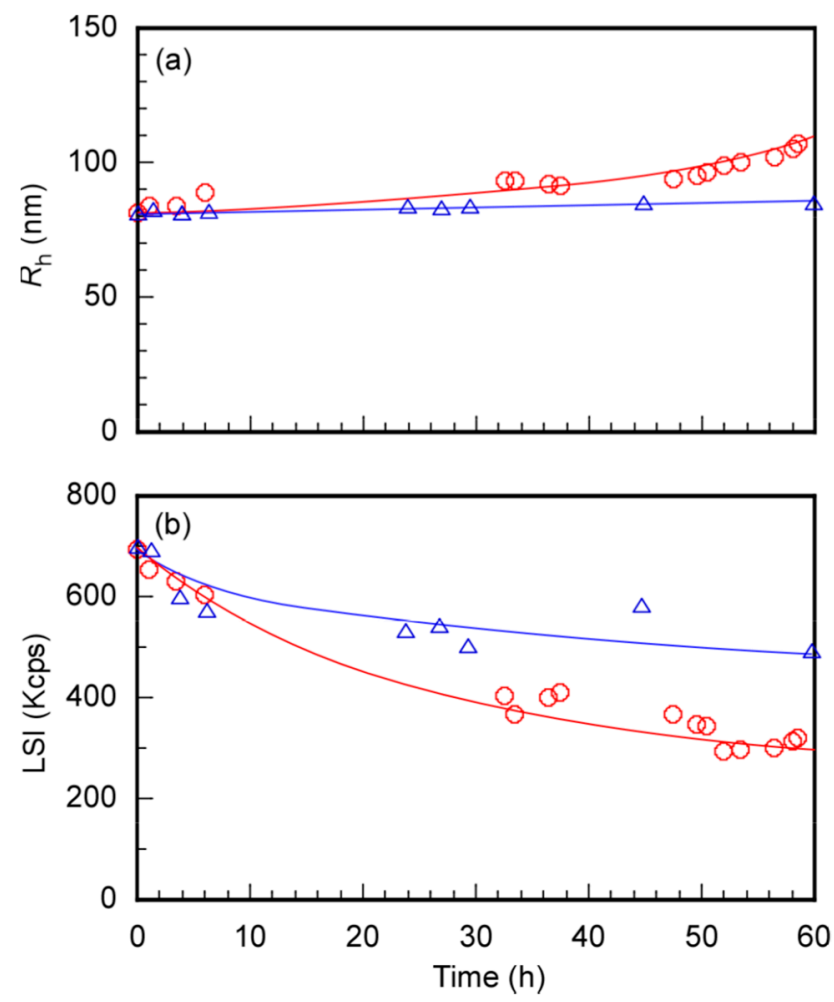

Figure 7. Time dependence on (a) hydrodynamic radius $\left(R_{\mathrm{h}}\right)$ and (b) light-scattering intensity (LSI) for $\mathrm{PEG}_{54}-\mathrm{P}(\mathrm{AA} / \mathrm{VE} 6 / \gamma \mathrm{TCP} 29)_{140}$ at $C_{\mathrm{p}}=0.10 \mathrm{~g} / \mathrm{L}$ at $25^{\circ} \mathrm{C}$ in acetate buffer of $\mathrm{pH} 5.2(\bigcirc)$ and in PBS buffer of $\mathrm{pH} 7.4(\triangle)$.
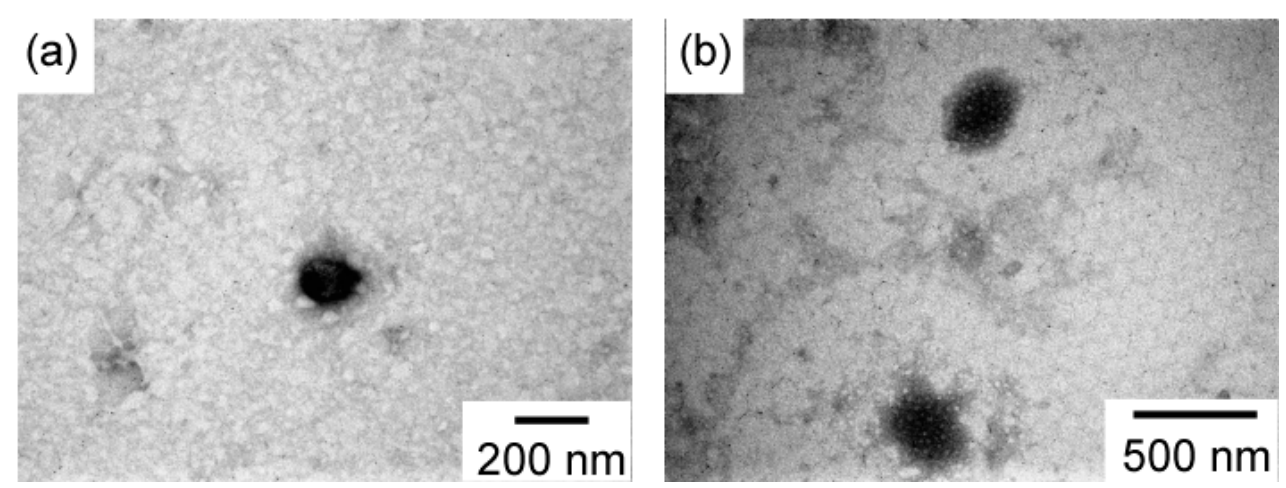

Figure 8. Transmission electron microscopy (TEM) images of $\mathrm{PEG}_{54}-\mathrm{P}(\mathrm{AA} / \mathrm{VE} 6 / \gamma \mathrm{TCP} 29)_{140}$ at $C_{\mathrm{p}}=0.10 \mathrm{~g} / \mathrm{L}$ in acetate buffer of $\mathrm{pH} 5.2(\mathbf{a})$ just after preparation and after (b) $60 \mathrm{~h}$.

\section{Conclusions}

The amphiphilic block copolymers of $\mathrm{PEG}_{54}-\mathrm{P}(\mathrm{AA} / \mathrm{VE} 6 / \gamma \mathrm{TCP} 29)_{140}$ bearing hydrophobic $\gamma \mathrm{TCP}$ via acetal bond linkage were prepared using RAFT radical polymerization. $\mathrm{PEG}_{54}-\mathrm{P}(\mathrm{AA} / \mathrm{VE} 6 / \gamma \mathrm{TCP} 29)_{140}$ were demonstrated to dissolve in water, forming polymer micelles composed of hydrophobic $\mathrm{P}(\mathrm{AA} / \mathrm{VE6} / \gamma \mathrm{TCP} 29)_{140}$ block cores and hydrophilic $\mathrm{PEG}_{45}$ shells. At $\mathrm{pH} 5.2$, a gradual increase 
in micelle size was observed with the gradual increase in time, attributed to the hydration and swelling of the core, which leads to the breakage of pendant acetal bonds. The breaking of acetal bonds generated $\gamma \mathrm{TCP}$ and pendant hydrophilic hydroxyl groups, which were hydrated and swollen to increase micelle size. At pH 7.4, the LSI of the polymer aqueous solutions decreased slightly with increasing time. This observation suggested that acetal bond was slightly degraded, even at $\mathrm{pH}$ 7.4. By applying $\mathrm{PEG}_{54}-\mathrm{P}(\mathrm{AA} / \mathrm{VE} 6 / \gamma \mathrm{TCP} 29)_{140}$ as a suitable polymer for cancer treatment, a slow release of $\gamma \mathrm{TCP}$ could be achieved. However, low concentrations of $\gamma \mathrm{TCP}$ show nontoxicity, as well as no side effects for healthy tissue; when $\gamma \mathrm{TCP}$ is released in large amounts around cancer tissue, pendant acetal linkages are effectively broken due to low $\mathrm{pH}$ values. Moreover, the high released concentrations of $\gamma \mathrm{TCP}$ from the polymer micelle present an alternative route in the treatment of cancer tissue in the absence of anticancer-drug usage, especially prostate cancer, with reduced side effects.

Supplementary Materials: The following are available online at http://www.mdpi.com/2073-4360/12/1/36/s1: Figure S1. (a) TEM images of $\mathrm{PEG}_{54}-\mathrm{P}(\mathrm{AA} / \mathrm{VE} 6 / \gamma \mathrm{TCP} 29)_{140}$ at $C_{\mathrm{p}}=0.10 \mathrm{~g} / \mathrm{L}$ in PBS buffer of $\mathrm{pH} 7.4$, in acetate buffer of pH 5.2 (b) just after preparation and (c) after $60 \mathrm{~h}$.

Author Contributions: Conceptualization, S.-i.Y. and T.O.; investigation, S.-i.Y., T.O., and S.Y.; preparation, S.Y.; measurements, S.Y., T.K., S.C., G.N.; writing—original-draft preparation, S.Y.; writing—review and editing, S.Y. and S.-i.Y.; supervision, S.-i.Y.; project administration, S.-i.Y.; funding acquisition, S.-i.Y.; S.Y., T.K., S.C., G.N., and T.O. contributed to the discussions. All authors have read and agreed to the published version of the manuscript.

Funding: This work was financially supported by a Grant-in-Aid for Scientific Research (25288101 and 16K14008) from the Japan Society for the Promotion of Science (JSPS), JSPS Bilateral Open Partnership Joint Research Projects, and the Research Program of "Dynamic Alliance for Open Innovation Bridging Human, Environment and Materials" in "Network Joint Research Center for Materials and Devices" (20194048).

Conflicts of Interest: The authors declare no conflict of interest.

\section{References}

1. Lefèvre, N.; Fustin, C.A.; Gohy, J.F. Polymeric micelles induced by interpolymer complexation. Macromol. Rapid Commun. 2009, 30, 1871-1888. [CrossRef] [PubMed]

2. Zhang, L.; Eisenberg, A. Ion-induced morphological changes in "crew-cut" aggregates of amphiphilic block copolymers. Science 1996, 272, 1777-1779. [CrossRef] [PubMed]

3. Nakashima, K.; Bahadur, P. Aggregation of water-soluble block copolymers in aqueous solutions: Recent trends. Adv. Colloid Interface Sci. 2006, 123, 75-96. [CrossRef] [PubMed]

4. Yokoyama, M.; Okano, T.; Sakurai, Y.; Kataoka, K. Improved synthesis of adriamycin-conjugated poly(ethylene oxide)-poly(aspartic acid) block copolymer and formation of unimodal micellar structure with controlled amount of physically entrapped Adriamycin. J. Control. Release 1994, 32, 269-277. [CrossRef]

5. Cabral, H.; Matsumoto, Y.; Mizuno, K.; Chen, Q.; Murakami, M.; Kimura, M.; Terada, Y.; Kano, M.R.; Miyazono, K.; Uesaka, M.; et al. Accumulation of sub-100 nm polymeric in poorly permeable tumors depends on size. Nat. Nanotechnol. 2011, 6, 815-823. [CrossRef]

6. Lammers, T.; Subr, V.; Ulbrich, K.; Peschke, P.; Huber, P.E.; Hennink, W.E.; Storm, G. Simulataneous delivery of doxorubicin and gemcitabine to tumors in vivo using prototypic polymeric drug carriers. Biomaterials 2009, 30, 3466-3475. [CrossRef]

7. Matsumura, Y.; Maeda, H. A new concept for macromolecular therapeutics in cancer chemotherapy: Mechanism of tumoritropic accumulation of proteins and the antitumor agent smancs. Cancer Res. 1986, 46, 6387-6392.

8. Deng, C.; Jiang, Y.J.; Cheng, R.; Meng, F.H.; Zhong, Z.Y. Biodegradable polymeric micelles for targeted and controlled anticancer drug delivery: Promiss, progress and prospects. Nano Today 2012, 7, 467-480. [CrossRef]

9. Hatakeyama, H.; Akita, H.; Harashima, H. A multifunctional envelope type nano device (MEND) for gene delivery to tumours based on the EPR effect: A strategy for overcoming the PEG dilemma. Adv. Drug Deliv. Rev. 2011, 63, 152-160. [CrossRef]

10. Hsiao, C.; Hsiao, G.; Chen, W.; Wang, S.; Chiang, C.; Liu, L.; Guh, J.; Lee, T.; Chung, C. Cephalochromin induces G0/G1 cell cycle arrest and apoptosis in A549 human non-small-cell lung cancer cells by inflicting mitochondrial disruption. J. Nat. Prod. 2014, 77, 758-765. [CrossRef] 
11. Kumazoe, M.; Sugihara, K.; Tsukamoto, S.; Huang, Y.; Tsurudome, Y.; Suzuki, T.; Suemasu, Y.; Ueda, N.; Yamashita, S.; Kim, Y.; et al. 67-kDa laminin receptor increases cGMP to induce cancer-selective apoptosis. J. Clin. Investig. 2013, 123, 787-799. [CrossRef] [PubMed]

12. Jiang, Q.; Wong, J.; Fyrst, H.; Saba, J.D.; Ames, B.N. $\gamma$-Tocopherol or combinations of vitamin E forms induce cell death in human prostate cancer cells by interrupting sphingolipid synthesis. Proc. Natl. Acad. Sci. USA 2004, 101, 17825-17830. [CrossRef] [PubMed]

13. Heinonen, O.; Albanes, D.; Vittamo, J.; Taylor, P.; Huttunen, J.; Hartman, A.; Haapa-koski, J.; Malila, N.; Rautalahti, M.; Ripatti, S.; et al. Prostate cancer and supplementation with $\alpha$-tocopherol and $\beta$-tocopherol. J. Natl. Cancer Inst. 1998, 90, 440-446. [CrossRef] [PubMed]

14. Noomura, A.; Stemmermann, G.; Lee, J. Serum micronutrients and prostate cancer in Japanese Americans in Hawaii. Cancer Epidemiol. Prev. Biomark. 1997, 6, 487-491.

15. Blomstrand, R.; Forsgren, L. Labelled tocopherols in man. Int. Z. Vitaminforschung 1968, 38, 328-344.

16. Coleman, C.N.; Mitchell, J.B.; Camphausen, K. Tumor hypoxia: Chicken, egg, or a piece of the farm? J. Clin. Oncol. 2002, 20, 610-615. [CrossRef]

17. Gu, Y.; Zhong, Y.; Meng, F.; Cheng, R.; Deng, C.; Zhong, Z. Acetal-linked paclitaxel prodrug micellar nanoparticles as a versatile and potent platform for cancer therapy. Biomacromolecules 2013, 14, 2772-2780. [CrossRef]

18. Wei, H.; Zhuo, R.X.; Zhang, X.Z. Design and development of polymeric micelles with cleavable links for intracellular drug delivery. Prog. Polym. Sci. 2012, 38, 503-535. [CrossRef]

19. Gillies, E.R.; Jonsson, T.B.; Frechet, J.M.J. Stimuli-responsive supramolecular assemblies of linear-dendritic copolymers. J. Am. Chem. Soc. 2004, 126, 11936-11943. [CrossRef]

20. Gillies, E.R.; Frechet, J.M.J. PH-responsive copolymer assemblies for controlled release of doxorubicin. Bioconjug. Chem. 2005, 16, 361-368. [CrossRef]

21. Chen, W.; Meng, F.H.; Cheng, R.; Zhong, Z.Y. PH-sensitive degradable polymersomes for triggered release of anticancer drug: A comparative study with micelles. J. Control. Release 2010, 142, 40-46. [CrossRef] [PubMed]

22. Simon, H.; Lien, H.; Benoit, L.; Lien, L.; Ruben, C.; Sabah, K.; Aaron, E.; Sunil, D.; Lutz, N.; Bert, S.; et al. Transiently thermoresponsive acetal polymers for safe and effective administration of anphotericin B as a vaccine adjuvant. Bioconjug. Chem. 2018, 29, 748-760.

23. Lampen, J. Amphotericin B and other polyenic antifungal antibiotics. Am. J. Clin. Pathol. 1969, 52, $138-146$. [CrossRef] [PubMed]

24. Gold, W.; Stout, H.A.; Pagano, J.F.; Donovick, R. Amphotericins A \& B, antifungal produced by a streptomycete. I. In vitro studies. Antibitics Ann. 1955, 3, 579-586.

25. Feng, L.; Chao, C.; Xixi, Y.; Xinyu, H.; Zhangyan, Z.; Jie, L.; Yue, Y.; Xianzhu, Y.; Jun, W. Acetal-linked hyperbranched polyphosphoester nanocarriers loaded with chlorin e6 for $\mathrm{pH}$-activatable photodynamic therapy. ACS Appl. Mater. Interfaces 2018, 10, 21198-21205.

26. Kang, J.; Zhang, X.Y.; Sun, L.D.; Zhang, X.X. Bioconjugation of functionalized fluorescent $\mathrm{YVO}_{4}$ : Eu nanocrystals with BSA for immunoassay. Talanta 2007, 71, 1186-1191. [CrossRef]

27. Ng, M.H.; Choo, Y.M.; Ma, A.N.; Chuah, C.H.; Hashim, M.A. Separation of vitamin E (tocopherol, tocotrienol, and tocomonoenol) in palm oil. Lipids 2004, 39, 1031-1035. [CrossRef]

28. Hadjichristidis, N.; Fetters, L.J. Effect of molecular weight and chain branching on the refractive index increment of polystyrene and polyisoprene solutions. J. Polym. Sci. Polym. Phys. Ed. 1982, 20, 2163-2166. [CrossRef]

29. Binboga, N.; Kisakurek, D.; Baysal, B.M. Effect of molecular weight on the refractive index increments of polystyrene, poly(ethylene glycol), poly(propylene glycol), and poly(dichlorophenylene oxide) in solution. J. Polym. Sci. Polym. Phys. Ed. 1985, 23, 925-931. [CrossRef]

30. Yamamoto, Y.; Nagasaki, Y.; Kato, Y.; Sugiyama, Y.; Kataoka, K. Long-circulating poly(ethylene glycol)-poly(D,L-lactide) block copolymer micelles with modulated surface charge. J. Control. Release 2001, 77, 27-38. [CrossRef]

31. Tanford, C.; Nozaki, Y.; Rohde, M.F. Size and shape of globular micelles formed in aqueous solution by n-alkyl polyoxyethylene ethers. J. Phys. Chem. 1977, 81, 1555-1560. [CrossRef] 
32. Yusa, S.; Yokoyama, Y.; Morishima, Y. Synthesis of oppositely charged block copolymers of poly(ethylene glycol) via reversible addition-fragmentation chain transfer radical polymerization and characterization of their polyion complex micelles in water. Macromolecules 2009, 42, 376-383. [CrossRef]

33. Burchard, W. Static and dynamic light scattering from branched polymers and biopolymers. Adv. Polym. Sci. 1983, 48, 1-124.

34. Konishi, T.; Yoshizaki, T.; Yamakawa, H. On the "universal constants" $\rho$ and $\phi$ of flexible polymers. Macromolecules 1991, 24, 5614-5622. [CrossRef]

35. Akcasu, Z.A.; Han, C.C. Molecular weight and temperature dependence of polymer dimensions in solution. Macromolecules 1979, 12, 276-280. [CrossRef]

36. Oho, H.; Yu, T.; Xu, L.X. Effects of several tea components on acid resistance of human tooth enamel. J. Dent. 1995, 23, 101-105.

(C) 2019 by the authors. Licensee MDPI, Basel, Switzerland. This article is an open access article distributed under the terms and conditions of the Creative Commons Attribution (CC BY) license (http://creativecommons.org/licenses/by/4.0/). 